\title{
RESEARCH
}

Open Access

\section{Development and validation of a formula for objective assessment of cervical vertebral bone age}

\author{
Raghavan Chandrasekar ${ }^{1,2^{*}}$ (D), Shyamala Chandrasekhar ${ }^{2}$, K. K. Shantha Sundari ${ }^{2}$ and Poornima Ravi ${ }^{1,3}$
}

\begin{abstract}
Background and aim: Determination of skeletal maturity and bone age from cervical vertebrae has been well documented. Most methods described use subjective evaluation of morphological characteristics of cervical vertebrae and may be prone to variability and error. A few objective methods have also been developed, specific for certain populations and genders. The aim of this study was to establish and validate an objective method to determine cervical vertebral bone age from lateral cephalometric radiographs, for Asian South Indian patients of both genders.
\end{abstract}

Methods: Ninety boys and 90 girls between 9 and 15 years of age were recruited, and their lateral cephalograms were taken. Using measurements made from the third and fourth cervical vertebrae, a formula to determine cervical vertebral bone age was derived using stepwise regression analysis. To validate the formula, a separate sample of 30 boys and 30 girls was chosen, and hand-wrist radiographs and lateral cephalograms were obtained. Cervical vertebral bone age (CVBA) was determined by applying the formula derived. Bone age was also calculated using the Tanner-Whitehouse 3 method. The bone ages determined by both methods were compared to each other and chronological age, using one-way ANOVA, Tukey's post hoc analysis, and Pearson's correlation coefficient.

Results: The formulae derived in the current study to determine CVBA differed for both genders. No statistically significant difference was found between CVBA, bone age derived by the Tanner-Whitehouse 3 method, and chronological age for both boys ( $p$ value $=0.425$ ) and girls ( $p$ value $=0.995)$. A moderate to strong positive correlation was found between CVBA, bone age, and chronological age.

Conclusion: The formulae derived in this study were validated and are reliable for objectively determining cervical vertebral bone age and skeletal maturation from lateral cephalograms for Asian South Indian patients of both genders.

Keywords: Bone age measurement, Cervical vertebral bone age, Skeletal age, Lateral cephalogram, Cervical vertebrae, Hand-wrist bones, Tanner-Whitehouse method

\footnotetext{
* Correspondence: drraghavanc@gmail.com

${ }^{1}$ Chandroo Dental Clinic, no.40, K.B Dasan road, Teynampet, Chennai 600018,

India

${ }^{2}$ Department of Orthodontics and Dentofacial Orthopedics, Saveetha Dental

College, Saveetha Institute of Medical and Technical Sciences, Saveetha

University, Chennai 600077, India

Full list of author information is available at the end of the article
}

\section{Springer Open}

(c) The Author(s). 2020 Open Access This article is licensed under a Creative Commons Attribution 4.0 International License, which permits use, sharing, adaptation, distribution and reproduction in any medium or format, as long as you give appropriate credit to the original author(s) and the source, provide a link to the Creative Commons licence, and indicate if changes were made. The images or other third party material in this article are included in the article's Creative Commons licence, unless indicated otherwise in a credit line to the material. If material is not included in the article's Creative Commons licence and your intended use is not permitted by statutory regulation or exceeds the permitted use, you will need to obtain permission directly from the copyright holder. To view a copy of this licence, visit http://creativecommons.org/licenses/by/4.0/. 


\section{Background}

Craniofacial growth is an integral part of orthodontic diagnosis and treatment planning. Growth is characterized by variation in the amount, rate, time, pattern, and progress towards maturity [1]. Evaluation of individual growth status, and predicting periods of accelerated growth, such as the pubertal growth spurt, is essential for treatment planning and can influence treatment outcomes in growth modulation procedures and dentofacial orthopedics [2]. For instance, correctly timing functional appliance treatment during the patient's accelerated growth period would provide the most optimal results in the correction of skeletal discrepancies [3].

The developmental status of a growing child can be assessed by various indicators, including chronological age, dental development, secondary sexual characteristics, peak height velocity, and skeletal maturation [2-5]. Chronological age is unreliable for assessment of developmental status because of the wide variation in timing and duration of the pubertal growth spurt and other developmental stages [6]. Radiographic assessment of the hand-wrist bones, by evaluation of ossification stages, is a reliable indicator of skeletal maturation and is found to be closely related to growth spurt [7-10]. Its main drawback, however, is that an additional radiograph is required $[6,11]$. Hand-wrist radiographs cannot be taken in newer imaging systems such as the EOS scanner, which has the advantage of minimizing radiation dose [12].

To reduce both radiation exposure and diagnostic cost to the patient, assessment of cervical vertebral maturation, as seen in routine lateral cephalograms, has been explored. Lamparski [13] was the first to suggest that morphological changes occurring in cervical vertebral bodies during growth could be used to assess skeletal maturation. He found that this method was a reliable and valid alternative to radiographic assessment of handwrist bones for determination of skeletal age, and this has been substantiated by several authors [3, 14-17].

Since then, cervical vertebral maturation method has been increasingly used to determine skeletal maturation in dentofacial orthopedics, without the need for handwrist radiographs $[2,3,18]$. However, these studies were based on subjective evaluation, where cervical vertebrae were evaluated comparing the patients' radiographic images with a standard atlas $[6,13]$. There are concerns that these methods may be prone to interoperator variability and error [6]. Objective methods of evaluation have been developed by certain authors using regression formulae based on ratios of measurements in the third and fourth cervical vertebral bodies [19, 20]. However, these formulae have been shown to vary with gender and racial origin [6].

Till date, there is inadequate literature on objective evaluation of CVBA in the Asian South Indian population.
The aim of the present study, therefore, was to establish and validate a formula in this population group that would determine the skeletal age from cervical vertebral maturation indicators.

\section{Materials and methods}

The present prospective cohort study was designed to derive a formula to determine cervical vertebral bone age for boys and girls of South Indian origin and validate the same. Ethical committee clearance was granted by the Institutional Review Board of Saveetha University. The sample for the study was chosen from patients visiting the Department of Orthodontics, Saveetha Dental College, for orthodontic treatment. Patients in the age group of 9 to 15 years, in good general health and of South Indian origin, were included for the study. Patients who had a history of trauma, surgical intervention, or severe systemic illness or those who showed malformation of the cervical vertebrae or hand bones were excluded. Eligible patients were recruited serially until the desired sample size was achieved. The nature of the study was explained to the patients and their parents, and informed consent was obtained. As this study was restricted to Asian South Indians, patients who had one or both parents belonging to other ethnicities were also excluded.

The study consisted of two phases. In the first phase, we attempted to derive a formula for determining the cervical vertebral bone age for both boys and girls. For this part, a total of 180 patients (90 boys and 90 girls), in the age group of $9-15$ years were recruited. Patients were divided into six age groups (9-10, 10-11, 11-12, $12-13,13-14,14-15$ years) with 30 patients in each group (15 boys and 15 girls). For all patients, digital lateral cephalograms were taken (Planmeca Promax Digital radiographic machine, AGFA Drystar 5300 printer).

Cephalometric analysis was done according to the method described by Mito et al. [19]. The outlines of C3 and $\mathrm{C} 4$ were traced using a $3 \mathrm{H}$ lead pencil on 0.03 " matte acetate paper, and all measurements were made using micrometer calipers. The following parameters were measured for both the vertebrae: anterior, middle, and posterior vertebral body heights and the anteroposterior body length. The depth of concavity was also assessed, as the distance between the deepest point of the curvature on the lower border to the lower border tangent (Fig. 1). All measurements were done by the same operator and were repeated after 10 days to assess for reliability. Intra-operator error between the two measurements was assessed using Dahlberg's formula.

Using the above measurements, seven ratios were calculated (Table 1). Pearson's correlation test was applied to these ratios and the patient's chronological age. The ratios which showed higher correlation with chronological age 


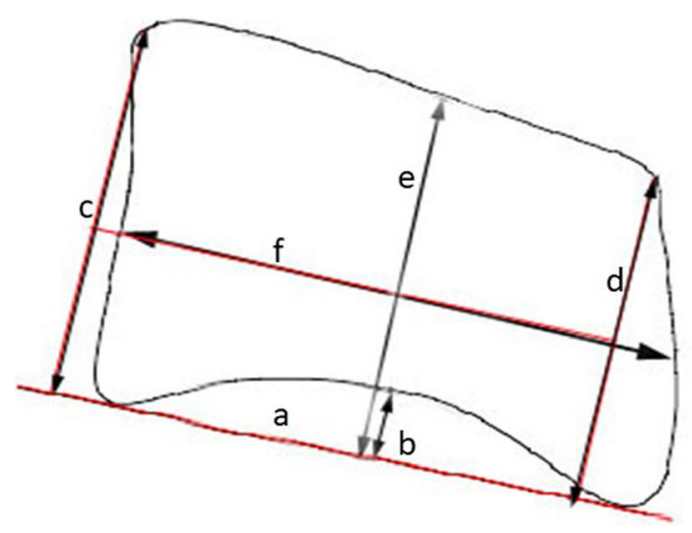

a - lower border tangent

b- depth of concavity

$c$ - anterior height

$\mathrm{d}$-posterior height

e- middle height

$f-$ anteroposterior width.

Fig. 1 Measurements made on the C3 and C4 cervical vertebrae

were used to derive a formula for objectively determining cervical vertebral bone age. This formula was then derived separately for boys and girls, through stepwise multiple regression analysis, using the selected ratios as independent variables and mean chronological age as the dependent variable.

The second phase of the study attempted to validate the formula that was derived in the first phase of the study. A different sample of sixty patients of both genders, in the age group of 9-15 years, was chosen from patients visiting the Department of Orthodontics, Saveetha Dental College. The inclusion criteria were the same as that of part 1 of the study. The sample was subdivided into two groups, 30 each for boys and girls. Digital lateral cephalograms and hand-wrist radiographs (Wipro GE CARES DX525 radiographic machine) were taken for all 60 patients.

All the 60 lateral cephalograms were analyzed. Cervical vertebral bone age (CVBA) was determined by applying the formulae derived during the first part of the study for both boys and girls. Hand-wrist radiographs were evaluated to determine bone age by Tanner

Table 1 Seven ratios that were assessed from the cephalogram

\begin{tabular}{ll}
\hline Ratio & Parameters assessed \\
\hline AH/AP & Anterior height/anteroposterior width \\
$\mathrm{PH} / \mathrm{AP}$ & Posterior height/anteroposterior width \\
$\mathrm{H} / \mathrm{AP}$ & Middle height/anteroposterior width \\
$\mathrm{AH} / \mathrm{PH}$ & Anterior height/posterior height \\
$\mathrm{AH} / \mathrm{H}$ & Anterior height/middle height \\
$\mathrm{H} / \mathrm{PH}$ & Middle height/posterior height \\
$\mathrm{CONC} / \mathrm{H}$ & Depth of concavity/middle height \\
\hline
\end{tabular}

The ratios were named according to the cervical vertebra measured; for instance, $\mathrm{AH} 3 / \mathrm{PH} 3$ refers to third cervical vertebra, while $\mathrm{AH} 4 / \mathrm{PH} 4$ refers to the fourth vertebra and Whitehouse method (TW3). Specific ossification centers of the radius, ulna, selected metacarpals, and phalanges were assessed, leading to their classifications into one of several stages. The scores were derived from each bone stage and calculated to compute the skeletal age or bone age.

The one-way ANOVA test was applied to identify differences between both the methods (cervical vertebral bone age and hand-wrist bone age) and the chronological age. To identify specific differences, the Tukey's post hoc test was used. The relationship between the cervical vertebral bone age and the other two groups was also determined using Pearson's correlation coefficient.

All the above statistical analysis was done using SPSS version 15 . The study power was set at $80 \%$ and a $p$ value of less than 0.05 was considered as significant ( $\alpha$ error-95\%).

\section{Results}

Analysis of the various parameters measured on third and fourth cervical vertebrae (Figs. 2, 3, 4, and 5) revealed that the depth of the concavity was very minimal between 9 and 10 years of age in both $\mathrm{C} 3$ and $\mathrm{C} 4$ among both boys and girls. The concavity gradually increased reaching a maximum between 13 and 14 years of age with minimum change till 15 years of age. This trend in growth was repeated with most of the other parameters, including anterior, middle, and posterior vertebral height and anteroposterior length of both $\mathrm{C} 3$ and $\mathrm{C} 4$ vertebrae. However, it was noted that the accelerated growth was distinct and pronounced in the posterior height of C3 in girls between 13 and 14 years of age, while for boys it was pronounced in the anterior and middle vertebral height.

Dahlberg's analysis for intra-operator reliability gave values between 0.092 and 0.599 . These values indicated adequate accuracy of measurement and reliability (DV $<1)$. 


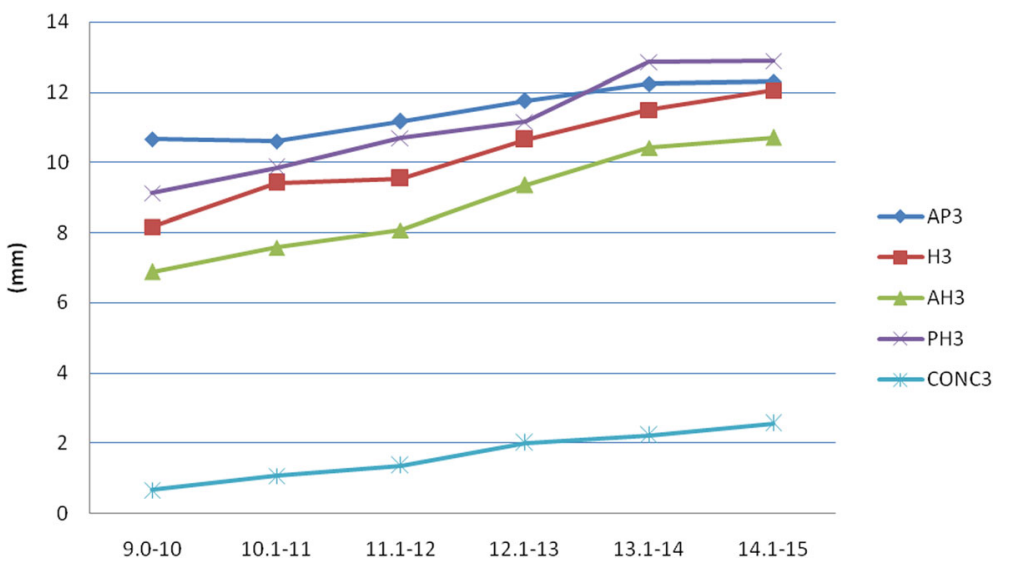

Fig. 2 Changes in the parameters of $\mathrm{C} 3$ in females $(\mathrm{AH}$, anterior height; $\mathrm{PH}$, posterior height; $\mathrm{H}$, middle height; $\mathrm{AP}$, anteroposterior length; $\mathrm{CONC}$, depth of concavity)

\section{Deriving a formula to calculate cervical vertebral bone age} Among the seven ratios established between the parameters measured for boys and girls separately, only five ratios in both genders showed a higher level of correlation with chronological age and were included in the formulae for determination of cervical vertebral bone age (CVBA). A gender variation was evident in the ratios selected for multiple regression analysis. Therefore, two separate formulae were derived to determine cervical vertebral bone age for boys and girls, through stepwise multiple regression analysis.

Cervical vertebral bone age for girls: $0.774+(4.033 \times$ $\left.\mathrm{PH}_{3} / \mathrm{AP}_{3}\right)-\left(0.087 \times \mathrm{H}_{3} / \mathrm{AP}_{3}\right)+\left(2.26 \times \mathrm{AH}_{3} / \mathrm{AP}_{3}\right)-(2.126$ $\left.\times \mathrm{AH}_{4} / \mathrm{AP}_{4}\right)+\left(8.513 \times \mathrm{AH}_{4} / \mathrm{H}_{4}\right)$

Cervical vertebral bone age for boys: $7.137+(3.695 \times$ $\left.\mathrm{AH}_{3} / \mathrm{AP}_{3}\right)-\left(1.582 \times \mathrm{H}_{3} / \mathrm{AP}_{3}\right)+\left(8.716 \times \mathrm{CONC}_{3} / \mathrm{H}_{3}\right)+$ $\left(1.753 \times \mathrm{AH}_{4} / \mathrm{AP}_{4}\right)+\left(1.604 \times \mathrm{H}_{4} / \mathrm{AP}_{4}\right)$

\section{Validation of the formula}

The results of comparisons between the cervical vertebral bone age, hand-wrist bone age, and chronological age are illustrated in Tables 2 and 3. The one-way ANOVA test did not show any significant difference between the three groups. When specific differences between each group were compared, Tukey's post hoc analysis also could not demonstrate any significant difference.

The correlation between cervical vertebral bone age and the other two groups is shown in Table 4. The values indicated that there was moderate to strong correlation between the cervical vertebral bone age and hand-wrist bone age, as well as the chronological age.

\section{Discussion}

The current study derived a formula to objectively determine cervical vertebral bone age (CVBA) in the Asian

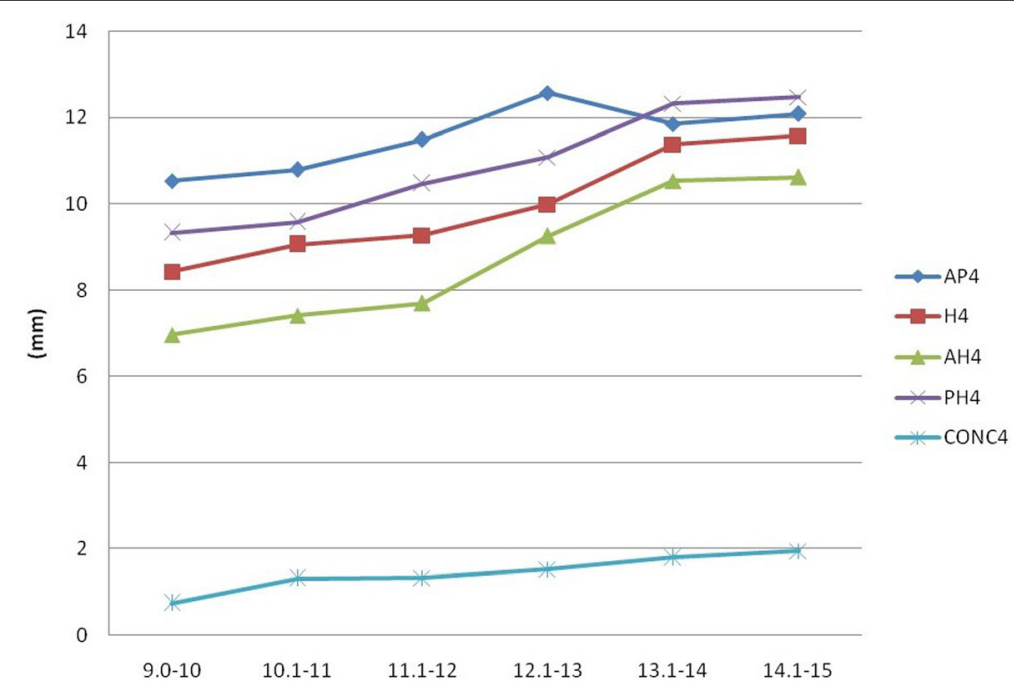

Fig. 3 Changes in the parameters of $\mathrm{C} 4$ in females (AH, anterior height, $\mathrm{PH}$, posterior height; $\mathrm{H}$, middle height; $\mathrm{AP}$, anteroposterior length; $\mathrm{CONC}$, depth of concavity) 


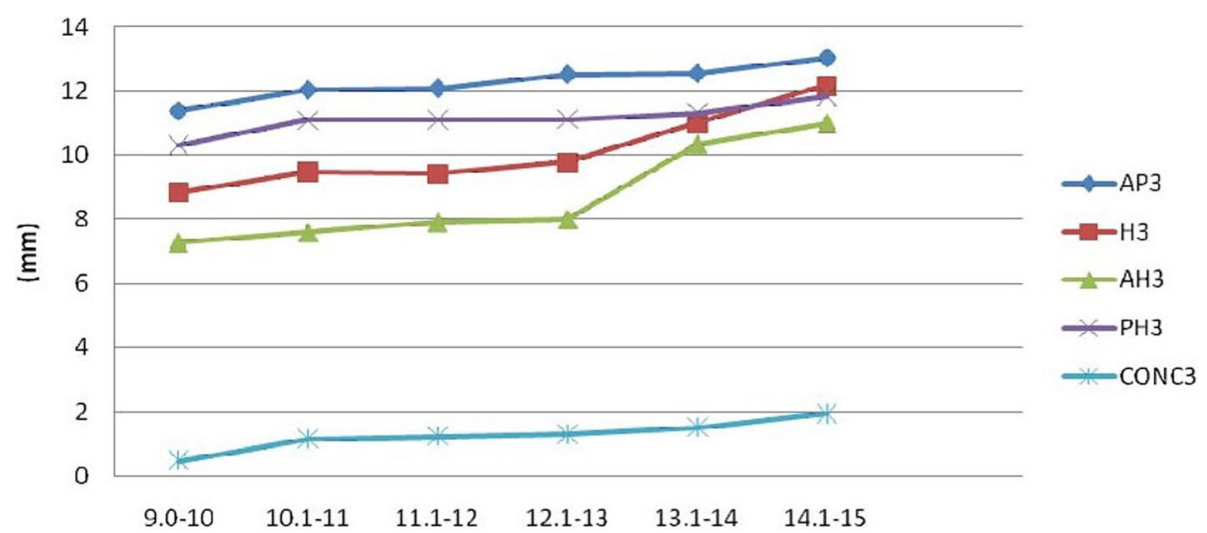

Fig. 4 Changes in the parameters of $\mathrm{C} 3$ in males (AH, anterior height; PH, posterior height; H, middle height; AP, anteroposterior length; CONC, depth of concavity)

South Indian population. Similar objective methods of determining CVBA have been utilized by previous researchers, in other ethnic groups. Mito et al. [19] was the first to suggest an objective method for determining CVBA, and their formula was derived for Japanese girls. However, when this formula was applied to Brazilian patients, Caldas et al. [6] noted that it was reliable only for Brazilian girls. Subsequently, they developed different formulae for both genders and validated these for use in the Brazilian population [20]. Kumar et al. also attempted to use Mito's formula for determining CVBA in the Asian North Indian population [21] and observed that it was reliable only for female patients. They stressed the need for developing a separate formula for males. Varshosaz et al. [22] derived a slightly different formula for the Iranian population.

The slight differences in formulae for the above studies could be explained by the fact that growth patterns tend to vary with race and gender. Zhang et al. [23] showed that ethnic and racial differences can affect growth patterns, and with subjective methods, bone age was overestimated in Asian and Hispanic populations. Therefore, it becomes necessary to identify objective methods of evaluating bone age specific to each ethnic group. Till date, no study exists for objectively evaluating cervical vertebral bone age in the Asian South Indian population. Indians, particularly South Indians, constitute one of the world's most significant diaspora. Deriving a specific formula for this population would be very relevant in the global scenario.

Although skeletal maturation usually occurs in all seven vertebrae, only the vertebral bodies of $\mathrm{C} 3$ and $\mathrm{C} 4$ were selected for measurements. The first cervical vertebra is not clearly visible, and the second cervical vertebra shows minimal morphological changes. Cervical vertebrae below $\mathrm{C} 4$ cannot be visualized when a thyroid protection collar is worn during radiation exposure $[6,19,20]$. To derive the formula, cervical vertebral ratios that were found to most closely correlate with the patient's chronological age were used. For both phases of the study, we chose patients

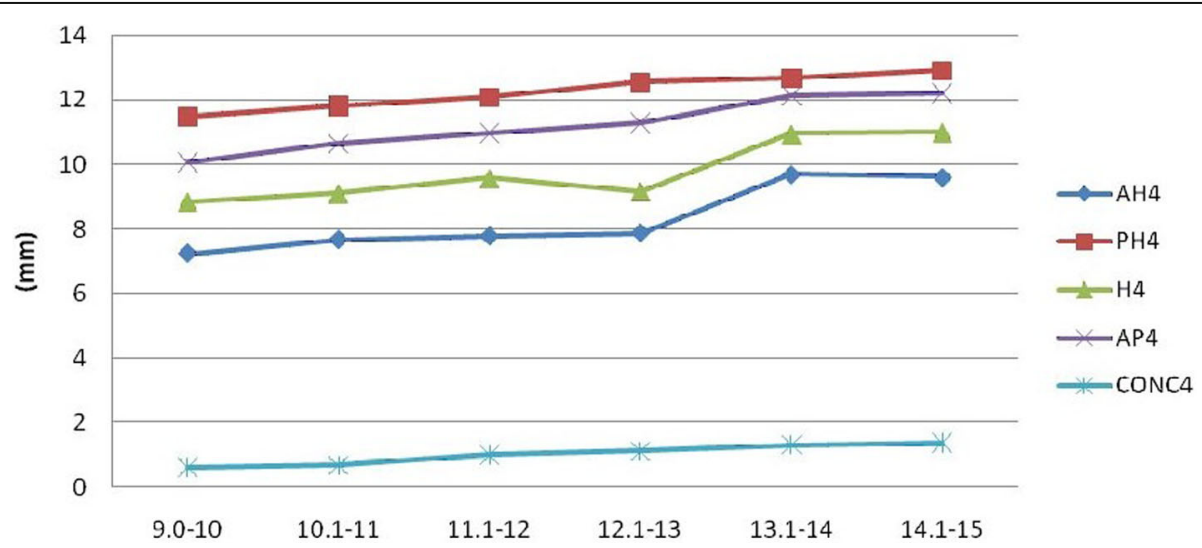

Fig. 5 Changes in the parameters of $\mathrm{C} 4$ in males $(\mathrm{AH}$, anterior height; $\mathrm{PH}$, posterior height; $\mathrm{H}$, middle height; $\mathrm{AP}$, anteroposterior length; $\mathrm{CONC}$, depth of concavity) 
Table 2 One-way ANOVA test comparing the calculated cervical vertebral bone age, hand-wrist bone age, and chronological age

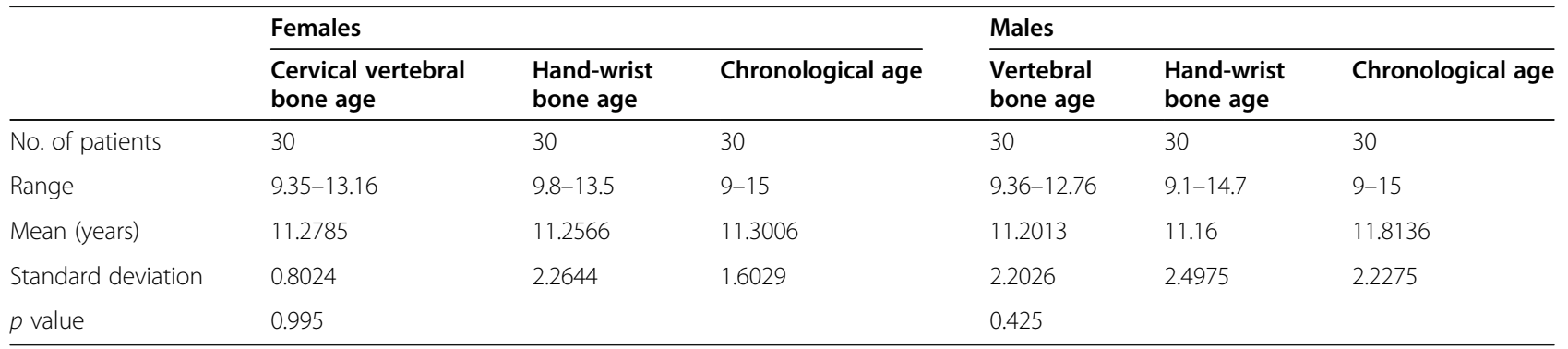

who were between 9 and 15 years of age, as this age range corresponds to prepubertal and pubertal growth phase in most patients, and this is when most patients seek orthodontic treatment. The same age range in both phases also ensured reliability of the formulae. We also analyzed male and female patients as separate groups. This was done to account for the differences in the timings of morphological changes in the cervical vertebrae between genders.

In the current study, for both genders, growth acceleration occurred between 13 and 14 years of age. This was reflected through changes in the anterior, middle, and posterior heights, as well as antero-posterior lengths. A distinct and pronounced growth was also noted in the posterior height of $\mathrm{C} 3$ in girls and anterior and middle height of $\mathrm{C} 3$ in males between 13 and 14 years of age. These findings contrast with those of Caldas et al., who noted that in their study, accelerated growth occurred in anterior, middle, and posterior height of $\mathrm{C} 3$ and $\mathrm{C} 4$ from 10 to 13 years in females [20]. In males, growth occurred in these regions only in $\mathrm{C} 3$, from 12 to 15 years of age, while there was no change in C4. Mito et al., on the other hand, observed that accelerated growth in the anterior, middle, and posterior height occurred between 10 and 13 years of age, in both C3 and C4 of girls [19]. These findings reflect that there is clear ethnic and gender variation in growth of the $\mathrm{C} 3$ and $\mathrm{C} 4$ cervical vertebrae.

The formula derived by stepwise regression analysis was found to be substantially different from other studies. For Japanese girls, the formula included ratio of anterior height to anteroposterior length and anterior height to posterior height [19]. The study in the Brazilian population focused on ratios of anterior height and middle height to anteroposterior length [20]. In the Iranian population, anterior vertical height alone was found to be a strong predictive factor. In the current formula, however, apart from these parameters, the ratio of the posterior height to anteroposterior length and the ratio of the lower border concavity to the middle height were also taken into account. The depth of concavity was not measured by the previous authors $[19,20,22]$. However, Roman et al. reported that lower border concavity of cervical vertebrae was the best morphological vertebral parameter to estimate skeletal maturation [11]. Therefore, it was measured in the current study, and its ratio with middle vertebral height yielded a significant correlation.

For validating the formula, the Tanner-Whitehouse 3 method was used for evaluation of bone age from handwrist radiographs [24]. The Tanner-Whitehouse 3 method is reproducible and reliable and is not as dependent on subjective evaluation as the Greulich and Pyle method, which involves comparison with an atlas [9]. It also allowed for easy comparison of estimated bone age with bone age calculated from cervical vertebrae. The current study showed good correlation between the values derived from both methods. The formulae established in the present study are therefore reliable for objectively determining cervical vertebral bone age and skeletal maturation from lateral cephalograms of Asian South Indian patients of both genders.

Establishing skeletal bone age from cervical vertebrae can in turn predict other variables that may be useful for treatment planning. For instance, Sato et al. found that mandibular growth potential could be accurately assessed based on CVBA, which was useful in planning the timing

Table 3 Tukey's ad hoc analysis comparing cervical vertebral bone age, hand-wrist bone age, and chronological age

\begin{tabular}{|c|c|c|c|c|}
\hline Comparison between & & & $\begin{array}{l}\text { Significance } \\
\text { (females) }\end{array}$ & $\begin{array}{l}\text { Significance } \\
\text { (males) }\end{array}$ \\
\hline \multirow[t]{2}{*}{ Cervical vertebral bone age } & vs & Hand-wrist bone age & 0.999 & 0.399 \\
\hline & & Chronological age & 0.999 & 0.879 \\
\hline \multirow[t]{2}{*}{ Hand-wrist bone age } & vs & Cervical vertebral bone age & 0.999 & 0.399 \\
\hline & & Chronological age & 0.994 & 0.694 \\
\hline \multirow[t]{2}{*}{ Chronological age } & vs & Cervical vertebral bone age & 0.999 & 0.879 \\
\hline & & Hand-wrist bone age & 0.994 & 0.694 \\
\hline
\end{tabular}


Table 4 Extent of correlation between different ages

\begin{tabular}{lll}
\hline Groups & $\begin{array}{l}\text { Correlation } \\
\text { coefficient } \\
\text { (females) }\end{array}$ & $\begin{array}{l}\text { Correlation } \\
\text { coefficient } \\
\text { (males) }\end{array}$ \\
\hline $\begin{array}{l}\text { Cervical vertebral bone age } \\
\text { and hand-wrist bone age }\end{array}$ & 0.408 & 0.674 \\
$\begin{array}{l}\text { Cervical vertebral bone age } \\
\text { and chronological age }\end{array}$ & 0.505 & 0.598 \\
\hline
\end{tabular}

of treatment, and treatment options in patients with class 3 malocclusions [25]. Studies have also shown that CVBA is correlated with dental eruption [26] and dental maturation of the lower permanent canine and second molar [27]. This can aid in orthodontic treatment planning.

\section{Limitations and future directions}

The main limitation of this study is that it was crosssectional, and measurements for all patients were only taken at one point in time. A longitudinal study would have allowed further validation of the formula at different stages of maturation. However, this would have led to further radiation exposure and may have been prone to attrition bias.

Most formulae generated for calculating cervical vertebral bone age in different ethnic groups are cumbersome and prone to error if worked out manually. The next logical step, as suggested by Caldas et al. [21], would be to develop a software that could automatically calculate CVBA for different ethnic groups based on measurements obtained from cervical vertebrae on lateral cephalograms. Research has already begun in this direction. Kok et al. recently compared the accuracy of different artificial intelligence algorithms for assessing cervical vertebral maturation [28]. However, a common platform that would include formulae for different ethnicities is needed; the world today is a global village and it is not uncommon for orthodontists to encounter young patients from different ethnic groups and populations.

In conclusion, the present study highlights that skeletal maturation indicators have slight variations across diverse ethnic groups, and may require different methods of objective evaluation. The formula derived in the current study has been validated for the Asian South Indian population and may be effectively used to determine cervical vertebral bone age from lateral cephalograms in this population.

\section{Abbreviations}

CVBA: Cervical vertebral bone age; TW3: Tanner-Whitehouse 3 method; C2, C3, C4: Second, third, and fourth cervical vertebrae; $\mathrm{AH}$ : Anterior height of cervical vertebral body; PH: Posterior height of cervical vertebral body; $\mathrm{H}$ : Middle height of cervical vertebral body; AP: Anteroposterior length of cervical vertebral body; CONC: Depth of concavity of cervical vertebral body
}

Authors' contributions

Study design: Dr. RC, Dr. SC, Dr. KKS. Recruitment of samples, obtaining Xrays: Dr. RC, Dr. KKS. Radiographic analysis and measurements: Dr. RC. Interpretation of data and statistical analysis: Dr. RC, Dr. SC, Dr. PR. Manuscript preparation: Dr. RC, Dr. SC, Dr. PR. Manuscript review and approval: Dr. RC, Dr. SC, Dr. KKS, Dr. PR. Accountability for author's contributions: Dr. RC, Dr. SC, Dr. KKS, Dr. PR. The author(s) read and approved the final manuscript.

Funding

None

\section{Availability of data and materials}

The datasets used and/or analyzed during the current study are available from the corresponding author on reasonable request.

\section{Ethics approval and consent to participate}

Ethical approval for this study was obtained from the Institutional Review Board, Saveetha University. Informed consent was obtained from all patients and their parents.

\section{Consent for publication}

Not applicable

\section{Competing interests}

The authors declare that they have no competing interests.

\section{Author details}

${ }^{1}$ Chandroo Dental Clinic, no.40, K.B Dasan road, Teynampet, Chennai 600018, India. ${ }^{2}$ Department of Orthodontics and Dentofacial Orthopedics, Saveetha Dental College, Saveetha Institute of Medical and Technical Sciences, Saveetha University, Chennai 600077, India. ${ }^{3}$ Department of Oral and Maxillofacial Surgery, Saveetha Dental College, Saveetha Institute of Medical and Technical Sciences, Saveetha University, Chennai, India.

Received: 5 June 2020 Accepted: 21 September 2020

Published online: 12 October 2020

\section{References}

1. Proffit WR, Fields H, Ackerman JL, Sinclair PM, Thoms PM, Tulloch CJF. Contemporary orthodontics. 2nd ed. St. Louis: Mosby; 1993. p. 18.

2. Baccetti T, Franchi $L$, Toth $L$, McNamara JA Jr. Treatment timing for twinblock therapy. Am J Orthod Dentofacial Orthop. 2000 Aug;118(2):159-70.

3. Baccetti T, Franchi L, McNamara JA Jr. The cervical vertebral maturation (CVM) method for the assessment of optimal treatment timing in dentofacial orthopedics. Semin Orthod. 2005;11(3):119-29.

4. Hassel B, Farman AG. Skeletal maturation evaluation using cervical vertebrae. Am J orthod Dentofacial orthop. 1995;107:58-60.

5. Uysal T, Ramoglu SI, Bascifitci FA, Sari Z. Chronological age and skeletal maturation of cervical vertebrae and hand-wrist - is there any relationship? Am J Orthod Dentofacial Orthop. 2006;130:622-8.

6. Caldas MP, Ambrosano GMB, Neto FH. Use of cervical vertebral dimensions for assessment of children growth. J Appl Oral sci. 2007;15(2):144-7.

7. Haag U, Tarangar J. Maturation indicators and pubertal growth spurt. Am J Orthods. 1982:82:299-309.

8. Fishman LS. Radiographic evaluation of skeletal maturation. A clinically oriented method based on hand-wrist films. Angle Orthod. 1982;52:88-112.

9. Greulich WW. Pyle JS. Radiographic atlas of skeletal development of handwrist: Stanford Standard University press; 1959.

10. Tanner JM, Whitehouse RH, Cameron N, Marshall WA Healy MJR, Goldstein $\mathrm{H}$. Assessment of skeletal maturity and prediction of adult height (TW2 method). $2^{\text {nd }}$ ed. London, Academic; 1983. p.22 - 37, 50 - 85.

11. Roman SP, Paima JC, Oteo MD, Nevado E. Skeletal maturation determined by cervical vertebrae development. Eur J Orthod. 2002;24:303-11.

12. O'Sullivan I, Schlégl ÁT, Varga P, Kerekes K, Vermes C, Than P. Bone agealternatives for skeletal maturity assessment for the EOS scanner. Orvosi hetilap. 2019 Apr 1;160(16):619-28.

13. Lamparski DG. Skeletal age assessment utilizing cervical vertebrae [dissertation]. Pittsburgh: University of Pittsburgh; 1972.

14. Garcia Fernandes $P$, Torre $H$, Flores $L$, Rea J. The cervical vertebrae as maturational indicators. J Clin Orthod. 1998;32:221-5. 
15. Flores-Mir C, Burgess BA, Champney M, Jensen RJ, Pitcher MR, Major PW. Correlation of skeletal maturation stages determined by cervical vertebrae and hand-wrist evaluations. Angle Orthod. 2006;76:1-5.

16. Gandini P, Mancini M, Andreani F. A comparison of hand wrist bone and cervical vertebral analyses in measuring skeletal maturation. Angle Orthod. 2006;76:984-9.

17. Wong RWK, Alkhal HA, Rabie ABM. Use of cervical vertebral maturation to determine skeletal age. Am J Orthod Dentofacial Orthop 2009; 136: 484.e1-484.e6.

18. Bacetti T, Franchi L. Mc Namara Jr JA. An improved version of the cervical vertebral maturation (CVM) method for assessment of mandibular growth Angle orthod. 2002;72:16-23.

19. Mito T, Sato K, Mitani H. Cervical vertebral bone age in girls. Am J Orthod Dentofacial Orthop. 2002;122(4):380-4.

20. Caldas MP, Ambrosano GMB, Neto FH. New formula to objectively evaluate skeletal maturation using lateral cephalometric radiographs. Braz Oral Res. 2007;21(4):330-5.

21. Kumar S, Agarwal N. Mehrotra A.K Evaluation of skeletal maturity in North Indian patients using an objective method based on cervical vertebral bone age and assessment of its reliability as compared to hand - wrist radiographic method. J Indian Orthod Soc. 2016;50:3-7.

22. Varshosaz M, Ehsani S, Nouri M, Tavakoli MA. Bone age estimations by cervical vertebral dimensions in lateral cephalometry. Progress in Orthodontics. 2012;13:126-31

23. Zhang A, Sayre JW, Vachon L, Liu BJ, Huang HK. Racial differences in growth patterns of children assessed on the basis of bone age. Radiology. 2009; 250(1):228-35. https://doi.org/10.1148/radiol.2493080468.

24. Tanner JM, Healy MJR, Goldstein H, Cameron N. Assessment of skeletal maturation and prediction of adult height (TW3 method) London, W.B Saunders; 2001.

25. Sato K, Mito T, Mitani H. An accurate method of predicting mandibular growth potential based on bone maturity. Am J Orthod Dentfacial Orthop. 2001:120:286-93

26. Vaida LL, Moca AE, Todor L, Țenț AD, Todor BI, Negruțiu BM, Moraru Al. Correlations between morphology of cervical vertebrae and dental eruption. Rom J Morphol Embryol. 2019 Jan 1;60(1):175-80

27. Kulkarni N, Dave B. Correlation of cervical vertebral bone age and Demirjian's stages of dental maturation for lower left permanent canine and second molar. J Contemp Dent Pract. 2019:20(4):471-5.

28. Kök H, Acilar AM, Izgi MS. Usage and comparison of artificial intelligence algorithms for determination of growth and development by cervical vertebrae stages in orthodontics. Prog Orthod. 2019 Dec 1;20(1):41.

\section{Publisher's Note}

Springer Nature remains neutral with regard to jurisdictional claims in published maps and institutional affiliations.

\section{Submit your manuscript to a SpringerOpen ${ }^{\circ}$ journal and benefit from:}

- Convenient online submission

- Rigorous peer review

- Open access: articles freely available online

- High visibility within the field

- Retaining the copyright to your article

Submit your next manuscript at $\boldsymbol{\nabla}$ springeropen.com 